\title{
The teaching of medical ethics
}

The first two articles under this general heading appeared in our second issue and described the teaching of medical ethics in Sweden and the United States of America. The following description of the situation in Maastricht in the Netherlands is unique as this is a new faculty of medicine and the opportunity has been taken to build the teaching of medical ethics into the curriculum from the start.

\section{In Maastricht, The Netherlands}

\section{Paul Sporken Faculty of Medicine, Maastricht, The Netherlands}

This contribution on the teaching of medical ethics in The Netherlands is characterized by two limitations. An exact description of the situation in seven of the Dutch faculties of medicine is impossible, since the necessary data are lacking. Therefore, I should like to focus on the new, eighth, medical faculty in Maastricht. This can in turn be an advantage for readers, for what I will discuss in this article is derived from a completely new type of medical education and training, and from the way in which medical ethics is embedded in this training programme.

A second limitation is that I cannot speak on behalf of all Dutch teachers of medical ethics but can only give my own opinions, the disadvantage of this approach being mitigated by the fact that my views are influenced by those of my colleagues concerned with ethics and medical ethics.

\section{Definition of 'ethics'}

For a correct definition of ethics it is necessary to consider the background of 'ethics'. The time has passed when ethics decided in detail what was the norm of good and evil. At the present time ethics can be described generally as the science which investigates human behaviour in relation to humanity and human dignity. The basic character of ethics is evaluative and not normative.

Ethical reflection contains three phases. The starting point of ethical reflection is the study of problems and of norms valid for those problems, or norms that are being proposed to be applied to the problems under study. In the second phase the investigation is of what fundamental human and social issues are basal to these norms: generally norms are set by humanistic views. As an example, the view that all human life must be unconditionally respected leads to the concrete norm that each abortion under all circumstances should be condemned in absolute terms. In the third phase a critical assessment of these humanistic views is taking place with a view to establishing authenticity and human values. For instance, what is the real meaning of the judgment of involuntary active euthanasia being good ethical conduct? What does it mean for our views on mankind, and our posture towards human beings? The evaluation of the human and social issues in turn leads to an evaluation of existing and proposed concrete norms. This description of ethics comes very close to that of Clarence Blomquist (1975), although there is a reverse order (empirical, meta- and normative ethics).

\section{Definition of medical ethics}

When medical ethics claims to belong to ethics, the discipline must not differ essentially from ethics in terms of methods and approaches. A difference can be found in the selection of problem areas: medical ethics deals with clearly defined issues health and disease, and all that is connected with health and disease. A number of colleagues define medical ethics correctly as 'ordinary ethics in a medical context or applied to the medical profession'. Personally I am convinced that something very important should be added to this definition, which can be exemplified by adding new developments in medical ethics.

For centuries, medical ethics was merely the code of honour for physicians. (Veatch and Fenner (1975) labelled this as 'medical etiquette'.) An evolution in this concept took place so that more attention began to be paid to fundamental ethical norms pertaining to the practice of medicine. This gave some grounds for using the connotation of 'medical', and this field of medical ethics could now focus on the personal and social aspects of physicians' behaviour. But a strong connexion has developed with 'social' ethics and to such an extent that the concept of 'socio-medical ethics' has emerged. Even in the latter view on medical ethics, the focus is more or less on the medical aspect of 
ethics and on the medical profession. This seems to be less correct. The time has come to extend this definition as a consequence of the natural evolution of the original concept.

Health and disease are more than a concern for the physician alone: health and disease are part of human existence and point to the relationship between the individual and his social environment. Therefore, medical ethics should be extended in two directions. In relation to ethical responsibility, it can be said that not only physicians but also all others in the field of health care, society, and last but not least the patient, bear responsibility for their own behaviour in terms of health and disease. And medical ethics should not be confined to the norms within the doctor-patient relationship and the incidental social aspects but its focus should be on the health of the individual and society, the personal and material living environment, the social facilities, the organization, objectives and structure of health care, and the policies of government in this field. Decisions about objectives and priorities are decisions on the human values which are part of health care. The medical ethics of the future should be developed into health care ethics, incorporating health care in all its facets as the objective of critical reflexion and evaluation.

We can find confirmation of the need for this change in the needs and demands of an ethical reflexion with the many workers in the health care field. In the following paragraphs we will, however, limit ourselves to the training of physicians.

\section{Medical ethics in The Netherlands}

In all faculties of medicine in The Netherlands attention is being paid to medical ethics, and in a number of cases a teacher is devoting some hours to its study. In other instances there is a teacher from another faculty (eg, a moral theologian from the Faculty of Theology or a philosopher, specializing in medical ethics). Sometimes the emphasis is on lectures and working groups or discussion groups. In The Netherlands the student's attendance at these lectures and tutorials is voluntary.

Although the teacher may profit by coming from another faculty, this very fact may prove to be disadvantageous to him: it is often clear that he has no voice in planning the curriculum and in the allocation of teaching hours. An attempt is sometimes made to improve this lamentable situation by urging the various teachers in the medical faculty to include ethics in the discussion of the issues in their own disciplines. Theoretically, there are a number of gains in this set up, but in fact nothing happens. In a number of cases the teacher of ethics is invited to attend interdisciplinary teaching sessions for advanced students, and this may eventually lead to the integration of medical ethics in the whole design of medical education. There is a lot of wishful thinking in this concept. Both strategies put a heavy constraint, in time and in $\overline{\bar{n}}$ energy, on the teacher of medical ethics, and hisẹ personal interests are often neglected. And what is $\Rightarrow$ more, medical ethics is being fragmented at the $\cos t \frac{\text { ? }}{9}$ of the necessary continuity.

The teaching programme in the Faculty of Medicine at Maastricht

Beyond any doubt, the newly designed teaching programme of the new Faculty of Medicine at:Maastricht can give a new impetus to the teaching $\vec{\omega}$ of medical ethics. To clarify further, a numbers of details of this teaching programme are offere here.

Four educational principles form the basis of the Maastricht curriculum: I) the curriculum is problem-orientated; 2) there is a continuous assessment system aimed at diagnostic formative evaluation; 3) students are expected to be active themselves in gaining knowledge and mastering skills; and 4) the curriculum focuses on the develop? ment of attitudes. It is clear, therefore, that the teaching programme in Maastricht is based ond concepts which are firmly rooted in educationat? theory and practice. Many reasons justify the choice of these principles - the information explosion, the departmentalization of disciplines in the traditionab medical curriculum, the role of memory and transfer in education, the motivation of students, the participation of students in their own education guided discovery as a learning principle and theip relevance in medicine and in medical education. $\overrightarrow{\vec{O}}$

When applying these principles to the construc 3 tion and development of a curriculum in medicine it is clear that lectures, practical courses an traditional clerkships can find no place, since the are seen to be in contradiction to the four basi principles, especially those concerned with problem orientation and self-activity.

For at least the first four years the basic mode o instruction is teaching in small groups adapted from the system already in operation at the Faculty of Medicine of McMaster University in Canada. In this plan, each unit or block covers a periad of four to. eight weeks during which the students, under the guidance of a tutor, try to achieve a number of predetermined goals and objectives. Instruction during these units is more a guided discussion than traditional instruction. In parallel there is, startin from the first year, a continuous clinical skillo programme which prepares the students for tho final period of practical extension of the knowledge and skills gained in the first part of the training programme.

The first year is composed of ro units of foup weeks each, under the general theme of introduction and orientation in medicine. The second year coverg the normal functioning of man, while the third and 
fourth years will cover the abnormal functioning of man and therapeutic action in illness and disease. Years five and six will be devoted to the practical extension of skills and knowledge and will mostly be related to the practice of medicine.

Since the Maastricht faculty aims at producing students familiar with the primary care of the patient, and hopes that many will select a career in family doctoring, much attention is being paid from the start of the programme to general practice, social work, and other related fields.

\section{Medical ethics in the educational programme at Maastricht}

The new programme, putting the emphasis on the incorporation of applied social sciences in the teaching of medical students, created the opportunity of establishing new chairs in medical psychology, medical sociology and medical ethics. By virtue of the existence of a 'basic philosophy' and the programme that originates from it, it is envisaged that these three disciplines will be integrated in the training of physicians. It should be noted that the interdisciplinarity element in the problem-orientated curriculum is an important asset in reaching this goal.

As in the autumn term of 1975, only the first- and second-year parts of the six-year curriculum are in operation, I can only describe the implementation of medical ethics in those parts of the training programme. However, I hope to present an impression of the present state and the area of the future developments.

The fourth unit in the first year is an introduction to and orientation towards primary medical care, including general practice, social work and domiciliary medicine. In that unit all students work with a general practitioner, a social worker or a home nurse. To ensure effectiveness in the teaching of the various roles and tasks in first-line care, students are asked to answer such questions as, "Which explicit or implicit norms have you noticed in the relations of rendering care that you have just observed?' (Implicit norms can be traced in expressions such as 'good' and 'bad', 'correct' and 'incorrect', 'be forced to'; values, 'you cannot do it that way', and the like.) In a meeting with the ethicist an inventory is drawn up of what has been observed. Through this mechanism students familiarize themselves with the method of ethical reflexion. To support discussions small portions of the relevant literature are added to the syllabus.

In the sixth unit, dealing with the psychosocial aspects of illness, both the teachers of sociology and medical ethics were videotaped during their conversations with parents of children with spina bifida. Students viewed these tapes while studying the factors that can disrupt daily life, eg, illness of one of the members of the family. The tape was also used as an example of the discussion of the ethical problems concerning the prolongation of life.

In the eighth unit, which was the first introduction to clinical medicine, the teacher of medical ethics was consulted repeatedly by a number of $\frac{\bar{c}}{\mathrm{~m}}$ students. Two student groups asked for guidance on the topic of the treatment of suicidal patients. Two other groups were impressed by the problems surrounding the information of patients and the right to die. All this led to discussions of considerable length. Summarizing, it can be said that this mode of action stimulates interdisciplinary cooperation between the basic sciences, clinical sciences and social sciences, cooperation between social scientists themselves, and incidentally, but regularly, the cooperation of teachers in other disciplines involved.

A last example is taken from the second-year programme. This year starts with a unit called 'from cell to individual', dealing with procreation and sexuality. As usual the topic is introduced to the students by means of medical or health problems, including such ethical 'heavyweights' as contraception, sterilization, artificial insemination and therapeutic abortion. It is impossible to elaborate extensively on all these subjects. The planning group responsible for this unit chose to include only one topic for discussion, namely, the human responsibility for one's own sexual experience Students are asked to write down their own opinions in the groups, and these reports serve as a starting point for further ethical reflexion. The thorough discussion of all these concrete problems will take place at a later stage of the curriculum.

\section{Conclusion}

Each innovative teaching programme contains a number of risks, and in the Maastricht programme there is hope for the future on the basis of our present experience and results. This also pertains to the teaching of medical ethics. Two goals can be realized with this programme. In the first place, students are able to apply the method of ethical reflexion, teaching themselves to take ethical decisions in a responsible way; secondly, students acquire the necessary ethical attitude that ill people will unconditionally rely upon.

\section{References}

Blomquist, C (1975). The teaching of medical ethics in Sweden. Fournal of medical ethics, $1,96-8$.

Veatch, R M, and Fenner, D (1975). The teaching of medical ethics in the USA. Fournal of medical ethics, I, 99-103. 